\title{
MOOD DISORDER QUESTIONNAIRE-INA: STUDI ADAPTASI ALAT UKUR SKRINING BIPOLAR
}

\author{
Hosea Gunawan $^{1}$, Monty P. Satiadarma ${ }^{2}$, Rita M. Idulfilastri ${ }^{3}$ \\ ${ }^{1}$ Program Studi Magister Psikologi Profesi, Universitas Tarumanagara Jakarta \\ Email: hosea.717181010@stu.untar.ac.id \\ ${ }^{2}$ Fakultas Psikologi, Universitas Tarumanagara Jakarta \\ Email: montys@fpsi.untar.ac.id \\ ${ }^{3}$ Fakultas Psikologi, Universitas Tarumanagara Jakarta \\ Email: ritamarkus@fpsi.untar.ac.id
}

Masuk : 29-02-2020, revisi: 28-04-2020, diterima untuk diterbitkan : 30-04-2020

\begin{abstract}
There are around 46 million people who had bipolar disorder in the world. The number of people diagnosed with bipolar disorder are also increaseasing. Misdiagnosis due to depression episode in bipolar disorder is also a common problem. This misdiagnosis could have a negative effect to the bipolar patient. One of the common way in detecting mania/hypomania in bipolar is using a screening tool. Mood Disorder Questionnaire (MDQ) is the most widely known and used for bipolar screening. However, bipolar screening tool is not commonly used because there was no available screening tool that has been develop or adapt correctly to be used in Indonesia. That is why the purpose of this study is to adapt the Mood Disorder Questionnaire in Indonesia. After MDQ is going through adaptation process, it is been try out to 20 participants with bipolar diagnosis and 20 participants without diagnosis. Try out data than been processed with SPSS 20.0. The result of reliability analysis shows a good result (13 items; $\alpha=.82$ ). MDQ-INA also show a good sensitivity $=.95$ and a good specificity $=.90$. Based on the results, $M D Q-I N A$ is good enough to be used as bipolar screening tool and can also be used in future research about bipolar or validation study.
\end{abstract}

Keywords: bipolar, mood disorder questionnaire, adaptation, screening tool

\begin{abstract}
ABSTRAK
Terdapat sekitar 46 juta orang di seluruh dunia memiliki gangguan bipolar. Di Indonesia sendiri peningkatan jumlah individu dengan diagnosis bipolar cukup banyak. Episode depresi yang mendominasi pada penderita bipolar seringkali menyebabkan kesalahan diagnosis yang diberikan dan hal ini berdampak buruk bagi individu tersebut. Oleh karena itu, salah satu cara untuk membantu mendeteksi symptom mania atau hypomania pada individu dengan bipolar adalah dengan menggunakan alat ukur skrining. Mood Disorder Questionnaire merupakan alat ukur skrining bipolar yang paling sering digunakan di seluruh dunia. Namun, di Indonesia belum ada alat ukur skrining yang dikembangkan maupun di adaptasi dengan baik sehingga penggunaan alat ukur skrining masih belum diberikan kepada pasien dengan kecenderungan bipolar. Tujuan penelitian ini adalah untuk mengadaptasi MDQ ke dalam bahasa Indonesia dan mendapatkan gambaran sensitivity dan specificity dari alat ukur skrining bipolar MDQ yang telah di adaptasi. Uji coba alat ukur diberikan pada 20 partisipan dengan diagnosis bipolar dan 20 partisipan tanpa diagnosis bipolar. Data yang diterima kemudian diolah menggunakan SPSS 20.0. Hasil pengolahan data menunjukkan skor reliabilitas yang baik (13 item; $\alpha=.82$ ). MDQ-INA juga menunjukan skor yang baik pada sensitivity $=.95$ dan specificity $=.90$. Berdasarkan hasil yang didapatkan MDQ-INA merupakan alat ukur yang layak untuk digunakan untuk skrining bipolar maupun digunakan pada penelitian mengenai bipolar maupun penelitian mengenai validasi alat ukur.
\end{abstract}

Kata Kunci: bipolar, mood disorder questionnaire, adaptasi, skrining

\section{PENDAHULUAN}

\section{Latar Belakang}

Berdasarkan data dari studi oleh the institute for health metrics and evaluation tahun 2017 (dalam Ritchie \& Roser, 2018), 0.6\% populasi dunia atau sekitar 46 juta orang di seluruh dunia memiliki gangguan bipolar. Gangguan bipolar adalah gangguan mental yang ditandai dengan adanya perubahan perasaan atau mood yang meningkat dengan signifikan (mania) dan kemudian dapat turun ke titik terendah (depresif). Perubahan emosi secara ekstrim dapat membuat individu 
merasa sangat terganggu dan akhirnya memilih untuk mengakhiri hidupnya (Kazdin, 2000). Berdasarkan hasil Riset Kesehatan Dasar (Riskesdas) pada tahun 2018 di Indonesia (Kementerian Kesehatan, 2018), ada peningkatan gangguan mental emosional di Indonesia menjadi 9,8\% dibandingkan dengan tahun 2013 yang hanya berkisar di angka $6 \%$ ("Memahami mereka yang hidup dengan bipolar," 2019).

Gangguan bipolar termasuk di dalamnya gangguan bipolar I, gangguan bipolar II, dan cyclothymic (American Psychiatric Association, 2013). Berdasarkan DSM 5 (American Psychiatric Association, 2013), gangguan bipolar II dapat diderita selama seumur hidup dengan setidaknya satu episode depresi berat dan setidaknya satu episode hypomanic, tidak lagi dianggap sebagai kondisi "lebih ringan" daripada gangguan bipolar I, terutama karena jumlah waktu individu dengan kondisi ini dihabiskan dalam depresi dan karena ketidakstabilan suasana hati yang dialami oleh individu dengan gangguan bipolar II biasanya disertai dengan gangguan serius dalam pekerjaan dan fungsi sosial (American Psychiatric Association, 2013).

Kesalahan diagnosis pada pasien bipolar II juga dapat berdampak buruk. Menurut McCraw, Parker, Graham, Synnott, dan Mitchell (dalam Smith, 2018), kesalahan diagnosis pada pasien bipolar II secara signifikan meningkatkan kemungkinan bunuh diri dan menimbulkan dampak negatif bagi pekerjaan, keuangan, penyalahgunaan obat-obatan, dan fungsi sosial. Bipolar disorder, terutama bipolar II juga seringkali di salah diagnosis yang menyebabkan pasien menerima treatment yang tidak optimal serta memberikan hasil yang tidak baik, bahkan simptom hypomanic seringkali disalahartikan sebagai perilaku efektif ataupun gaya pribadi seseorang (Leung et al., 2016).

Simptom bipolar yang meliputi perilaku impulsif, alkohol and penyalahgunaan zat berbahaya, peningkatan energi berlebih, dan masalah hukum seringkali dikaitkan dengan gangguan lain di luar bipolar (Hirschfeld et al., 2000). Menurut Ibu V (personal communication, September 3, 2019), banyak penderita bipolar yang tergabung dalam komunitasnya di diagnosis dengan depresi, bahkan hal ini juga dirasakan oleh dirinya yang dahulu mendapatkan diagnosis depresi selama hampir setahun. Hal ini dapat terjadi karena profesional dalam bidang klinis seringkali tidak memastikan kemunculan simptom hypomania ataupun mania pada pasien. Hal ini disebabkan oleh simptom yang terlihat jelas pada pasien saat menemui profesional adalah simptom depresi dan hal ini akan menuntun pada pemberian diagnosa yang keliru (Yang et al., 2011). Selain itu, fenomena self-diagnosis sebagai penderita bipolar juga meningkat, hal ini biasanya dilakukan untuk mengikuti trending di internet bahkan digunakan sebagai alasan untuk mengkompensasi perilaku moody ataupun marah-marah yang menyebabkan lingkungan sekitar tidak nyaman, sebagai efek dari gangguan bipolar (V, personal communication, September 3, 2019). Oleh karena itu, proses dan cara untuk mendiagnosis bipolar harus tepat, cepat serta dinilai sangat penting untuk mengurangi kemungkinan munculnya dampak negatif dari diagnosis keliru yang terjadi.

Salah satu cara untuk meningkatkan kesadaran terhadap suatu gangguan adalah dengan melakukan skrining. The Mood Disorder Questionnaire merupakan salah satu kuesioner yang dapat digunakan untuk membantu skrining pasien dengan gangguan bipolar. MDQ merupakan sebuah kuesioner self-report yang dicetak pada satu halaman kertas dan terdiri dari 13 pertanyaan dengan pilihan jawaban "yes" atau "no", kemudian ditambah dengan 1 pertanyaan yang memiliki 4 poin skala jawaban (Leung et al., 2016). Kuesioner ini juga dinilai dapat meringankan dan mengingatkan para profesional di bidang klinis untuk memastikan kemunculan simptom hypomania atau mania pada pasien yang diduga memiliki bipolar maupun 
menunjukkan simptom depresi (Yang et al., 2011). Simptom mania ditandai dengan hiperaktivitas, peningkatan self-esteem, grandiosity, berkurangnya waktu tidur, bahkan munculnya psychotic symptom. Sedangkan hypomania merupakan bentuk mania yang lebih pendek durasinya, biasanya individu dalam episode hypomania masih memiliki penilaian yang baik (Vieta et al., 2018).

Hasil validasi terhadap alat ukur ini pada 198 pasien juga menunjukkan angka konsistensi internal atau reliabilitas yang baik (13 item, $\alpha=.90$ ), bahkan 7 dari 10 orang dengan bipolar dapat di identifikasi dengan tepat serta 9 dari 10 orang yang tidak memiliki diagnosis gangguan bipolar dapat di saring keluar (Leung et al., 2016). Berdasarkan Canadian Network for Mood and Anxiety Treatment Guidelines, MDQ masih dianggap sebagai alat ukur skrining yang sangat berguna untuk membantu dalam diagnosis pasien dengan gangguan bipolar (Yang et al., 2011). Selain itu MDQ telah di adaptasi dan di validasi dalam beberapa bahasa serta digunakan pada beberapa negara selain negara asal MDQ, seperti dalam bahasa Finnish di Finland (Isometsä et al., 2003), dalam bahasa Spanyol (Sanchez-moreno et al., 2008), dalam bahasa Portugis (De Sousa Gurgel et al., 2012), dalam bahasa Chinese Simplified di negara China (Yang et al., 2011), dan juga dalam bahasa Thai di negara Thailand (Waleeprakhon et al., 2014).

Walaupun MDQ merupakan alat ukur skrining yang paling sering digunakan di seluruh dunia untuk skrining gangguan bipolar (Hirschfeld, 2010), namun di Indonesia, MDQ maupun alat ukur skrining lainnya yang dapat membantu diagnosa gangguan bipolar masih belum banyak digunakan bahkan belum ada. Salah satu alasan tidak digunakannya alat ukur skrining dalam membantu diagnosa awal bipolar adalah belum adanya adaptasi yang memadai mengenai kuesioner MDQ. Menurut Bracken dan Barona dalam Krach et al. (2017), adaptasi alat tes terdiri dari beberapa langkah, yaitu : (a) word-for-word translation, alat tes di translasi ke dalam bahasa yang ditargetkan oleh individu dengan kemampuan bilingual; (b) back translation, menempatkan individu yang tidak mengenal alat tes yang sebenarnya untuk mentranslasi kembali ke dalam bahasa awal tes tersebut; (c) approval of test committee, mengundang pakar dalam bidang tertentu dan memiliki kemampuan bilingual untuk menguji keakuratan konten dan juga konstruk dari alat tes yang telah melalui proses translasi; (d) pilot study (try out), melakukan pengujian awal pada target populasi. Oleh karena itu, penelitian ini bertujuan untuk memberikan kontribusi dalam mengadaptasi dan memberikan informasi ilmiah mengenai Mood Disorder Questionnaire sebagai alat ukur skrining untuk gangguan bipolar.

Berdasarkan fenomena yang telah dijelaskan di atas, maka peneliti merumuskan masalah pada penelitian ini yaitu apakah Mood Disorder Questionnaire (MDQ) dapat diadaptasi ke dalam bahasa Indonesia dan dapat digunakan untuk skrining gangguan bipolar.

\section{METODE PENELITIAN}

\section{Partisipan dan Prosedur Penelitian}

Karakteristik partisipan penelitian ini adalah individu yang memiliki diagnosis gangguan bipolar yang diberikan oleh Psikolog maupun Psikiater serta lahir di Indonesia dan dapat memahami bahasa Indonesia. Partisipan berusia minimal 18 tahun, namun tidak dibatasi laki-laki maupun perempuan dan juga harus dapat menyelesaikan seluruh kuesioner yang diberikan. Karakteristik pada partisipan dalam control group (grup pembanding) adalah tidak memiliki diagnosis gangguan bipolar serta lahir di Indonesia dan dapat memahami bahasa Indonesia. Individu yang telah memiliki diagnosis gangguan bipolar dari Psikolog atau Psikiater berasal dari komunitas " $\mathrm{x}$ " dan berjumlah 20 orang dan jumlah individu dalam kelompok pembanding adalah 20 orang. Teknik pengambilan sampel yang digunakan dalam penelitian ini adalah metode non-probability 
sampling dengan teknik purposive sampling yang merupakan pengambilan sampel secara sengaja berdasarkan keperluan penelitian.

Dalam proses adaptasi, hal yang terutama adalah mendapatkan izin dari pembuat alat ukur. Setelah mendapatkan izin dari Professor Hirschfeld yang merupakan professor psychiatry di Weill Cornel Medical College dan juga penyusun dan pengembang dari Mood Disorder Questionnaire (MDQ), peneliti melakukan persiapan adaptasi yang diperlukan. Proses adaptasi dimulai dengan translasi butir-per-butir dari bahasa Inggris ke dalam bahasa Indonesia oleh penerjemah tersumpah. Kemudian butir dalam bahasa Indonesia di terjemahkan kembali (back translate) oleh individu dengan kemampuan bilingual dan berlatar belakang studi psikologi tetapi individu tersebut harus tidak memiliki pengalaman tentang alat ukur MDQ sebelumnya dan dalam penelitian ini adalah dosen di fakultas psikologi Tarumanagara. Kemudian penyesuaian bahasa dilakukan sampai hasil back translate memiliki makna serupa dengan kuesioner asli. Kemudian kuesioner dalam bahasa Indonesia di evaluasi oleh pakar dalam psikologi dengan syarat telah menempuh pendidikan Doktor atau S3 dalam bidang psikologi klinis dan juga oleh psikiater. Dalam penelitian ini para pakar terdiri dari 4 orang Psikolog dengan gelar Doktor di dalam bidang psikologi klinis dan 1 orang dokter spesialis kejiwaan atau psikiater. Masukan yang didapatkan dari para pakar digunakan untuk memperbaiki bahasa dan ketepatan dalam kemampuan butir dalam mengukur.

Kemudian uji coba alat ukur MDQ dalam bahasa Indonesia atau yang selanjutnya disebut sebagai MDQ-INA dilakukan kepada partisipan penelitian. Kemudian data yang didapatkan diolah dengan SPSS 20.0 untuk di uji reliabilitas dan juga dilakukan pengujian ROC Curve. Analisis ROC curve dilakukan untuk melihat kemampuan diskriminatif suatu alat tes dalam melakukan skrining melalui skor sensitivity dan specificity yang dimiliki (Karr et al., 2018). Sensitivity atau true positive rate, merupakan pengukuran untuk menentukan kemampuan suatu alat tes dalam mendeteksi individu dengan target karakteristik atau kondisi tertentu. Sedangkan specificity atau true negative rate, merupakan pengukuran untuk menentukan secara tepat individu tanpa diagnosis atau keadaan yang ditargetkan (Søreide et al., 2011).

\section{Instrumen Penelitian}

Mood Disorder Questionnaire (MDQ) merupakan alat ukur skrining bipolar yang dikembangkan oleh Hirschfeld et al. (2000). MDQ merupakan self-reported test yang dapat dikerjakan dalam waktu singkat. MDQ melakukan skrining terhadap histori manic maupun hypomanic melalui 13 butir item dengan pilihan jawaban yes atau no (Hirschfeld et al., 2000). Setelah dilakukan pengujian terhadap 109 pasien yang terdiri dari 70 orang dengan bipolar-I, 26 orang dengan bipolar-II, 13 orang dengan bipolar NOS, dan selebihnya pasien tanpa diagnosa bipolar, MDQ menunjukkan hasil yang baik, yaitu sensitivity $=.73$ dan specificity $=.90$, pada skor minimal 7 (Hirschfeld et al., 2000). Dalam penelitian lanjutan oleh Hirschfeld et al. (2003), MDQ juga menunjukkan internal konsistensi atau reliabilitas yang baik (13 item, $\alpha=.84$ ). Dalam penelitian ini digunakan versi bahasa Indonesia atau MDQ-INA yang sudah di jelaskan proses translasi dan evaluasi pada paparan sebelumnya

\section{Teknik Pengolahan Data}

Data yang didapatkan melalui partisipan untuk try out alat ukur MDQ-INA kemudian di olah menggunakan SPSS 20.0 menggunakan uji reliabilitas Cronbach's Alpha. Berdasarkan pengujian tersebut didapatkan skor reliabilitas yang baik (13 item, $\alpha=.82>.70$ ), yang artinya setiap MDQ-INA dapat dengan konsisten mengukur apa yang hendak diukur. Hasil pengujian ROC Curve (Tabel 1) memberikan beragam skor sensitivity dan specificity dari nilai cut-off yang 
beragam. Penentuan nilai cut-off minimal 6.5 yang dalam alat ukur ini berarti menjawab ya pada minimal 7 pertannyaan ditentukan melalui nilai Youden Index yang tertinggi. Rumus Youden Index dapat dilihat pada Rumus nomor 1.

Rumus 1.

Youden Index $=$ TPF (Sensitivity) - FPF $(1-$ Specificity $)$

Tabel 1. Analysis ROC Curve

\begin{tabular}{llll}
\hline $\begin{array}{l}\text { Nilai Cut-off } \\
\text { (lebih dari / sama } \\
\text { dengan) }\end{array}$ & Sensitivity & 1-Specificity & $\begin{array}{l}\text { Youden } \\
\text { Index }\end{array}$ \\
\hline 0.5 & 1.000 & & \\
2.0 & 1.000 & .850 & .150 \\
3.5 & 1.000 & .700 & .300 \\
4.5 & 1.000 & .450 & .550 \\
5.5 & 1.000 & .400 & .600 \\
$\mathbf{6 . 5}$ & .950 & .300 & .700 \\
7.5 & .650 & .100 & .850 \\
8.5 & .550 & .100 & .550 \\
9.5 & .450 & .050 & .500 \\
10.5 & .250 & .000 & .450 \\
11.5 & .150 & .000 & .250 \\
12.5 & .050 & .000 & .150 \\
14.0 & .000 & .000 & .050 \\
\hline
\end{tabular}

\section{HASIL DAN PEMBAHASAN}

Pada penelitian ini proses awal adaptasi alat ukur skrining MDQ yang telah melalui proses translasi dan evaluasi oleh pakar di susun menjadi MDQ-INA yang kemudian di ujikan kepada 40 partisipan penelitian yang terdiri dari 20 partisipan dengan diagnosis gangguan bipolar dan 20 partisipan tanpa diagnosis gangguan bipolar. Data yang didapatkan kemudian diolah dengan pengujian reliabilitas dan ROC Curve. Berdasarkan pengujian tersebut, mendapatkan hasil bahwa MDQ-INA memiliki konsistensi internal yang baik atau setiap butir dapat mengukur hal yang sama dan konsisten. Kemudian pengujian ROC Curve memberikan referensi nilai cut-off 6.5, artinya individu dapat di skrining positif apabila menjawab "ya" pada minimal 6.5 atau pada nilai sesungguhnya 7. MDQ-INA juga memiliki skor sensitivity $=.95$, artinya MDQ-INA dapat mendeteksi 95\% pasien dengan dengan simptom manic/hypomanic. MDQ-INA juga memiliki skor specificity $=.90$, artinya MDQ-INA dapat menyaring keluar individu tanpa kondisi tertentu.

MDQ-INA menunjukkan reliabilitas yang baik (13 item, $\alpha=.82$ ), namun masih belum dapat mereplikasi skor reliabilitas MDQ versi asli (13 item, $\alpha=.84$ ) (Hirschfeld et al., 2000), hal ini dapat disebabkan oleh masih minimnya jumlah partisipan dalam uji coba alat ukur ini. Namun MDQ-INA dapat mengungguli nilai cronbach's alpha dari adaptasi MDQ dalam beberapa versi lainnya, seperti pada Finnish version (13 item, $\alpha=$.79) (Isometsä et al., 2003) dan juga pada Thai version (13 item, $\alpha=.79$ ) (Waleeprakhon et al., 2014). Oleh karena itu, MDQ-INA dapat disimpulkan memiliki internal konsistensi atau reliabilitas yang baik dan dapat dipertanggung jawabkan. 
MDQ-INA juga memiliki nilai sensitivity $=.95$ dan specificity $=.90$ yang sangat baik. MDQINA dapat menggungguli versi asli dari MDQ dengan sensitivity $=.70$ dan specificity $=.90$ (Hirschfeld et al., 2000). Kemudian, MDQ-INA juga dapat mengungguli beberapa versi adaptasi di negara lain, seperti pada versi Chinese dengan sensitivity $=.73$ dan specificity $=.88$ (Chung et al., 2008) dan juga versi Turkish dengan sensitivity $=.64$ dan specificity $=.77$ (Konuk et al., 2007).

Penelitian ini tentu saja memiliki kelebihan dan juga limitasinya. Kelebihan dalam penelitian ini adalah alat ukur MDQ telah di adaptasi menggunakan prosedur yang tepat dan juga telah di evaluasi oleh para pakar dalam bidang dan pendidikan yang memadai. Namun tentu saja limitasinya adalah masih minimnya partisipan yang digunakan dalam proses uji coba. Oleh karena itu disarankan dalam penelitian lanjutan dapat melakukan validasi MDQ-INA menggunakan partisipan yang lebih banyak. Penelitian berikutnya juga dapat menggunakan pengujian validitas butir dengan Confirmatory Factor Analysis (CFA) untuk membuktikan variabel-variabel teramati yang diukur melalui butir dapat merefleksikan variabel latennya (Idulfilastri, 2018).

\section{KESIMPULAN DAN SARAN}

Berdasarkan hasil adaptasi yang dilakukan dalam penelitian ini, yang dimulai dari proses translasi kata-per-kata, back translate, evaluasi penyesuaian, expert judgment, dan uji coba pada partisipan, dapat disimpulkan bahwa MDQ-INA layak digunakan untuk membantu proses skrining gangguan bipolar dan juga untuk keperluan penelitian lebih lanjut.

\section{Ucapan Terima Kasih (Acknowledgement)}

Terima kasih kepada Ibu Vindy dari komunitas "X" yang telah memberikan izin dan membantu dalam proses pengambilan data untuk penelitian ini. Terima kasih juga kepada Professor Hirschfeld atas izin adaptasi Mood Disorder Questionnaire (MDQ) dan juga atas saran serta evaluasi selama proses penelitian. Terima kasih kepada Ibu Meylisa Permatasari, M.Sc., yang telah membantu dalam proses translasi alat ukur dalam penelitian ini. Terima kasih kepada Dr. Lidia Laksana Hidajat, MPH., Psikolog, Dr. Retha Arjadi, M.Psi., Psikolog, Dr. Christin Wibhowo, M.Si., Psikolog, dan dr. Henny Riana, Sp.KJ. atas nasehat dan evaluasi kepakaran yang telah diberikan dalam penelitian ini.

\section{REFERENSI}

American Psychiatric Association. (2013). Diagnostic and statistical manual of mental disorders (DSM-5®). American Psychiatric Pub.

Chung, K. F., Tso, K. C., Cheung, E., \& Wong, M. (2008). Validation of the Chinese version of the Mood Disorder Questionnaire in a psychiatric population in Hong Kong. Psychiatry and Clinical Neurosciences, 62(4), 464-471. https://doi.org/10.1111/j.14401819.2008.01827.x

De Sousa Gurgel, W., Rebouças, D. B., Negreiros De Matos, K. J., Carneiro, A. H. S., \& Gomes De Matos E Souza, F. (2012). Brazilian Portuguese validation of Mood Disorder Questionnaire. Comprehensive Psychiatry, 53(3), 308-312. https://doi.org/10.1016/j.comppsych.2011.04.059

Hirschfeld, R. M.A., Williams, J. B. W., Spitzer, R. L., Calabrese, J. R., Flynn, L., Keck, J., Lewis, L., McElroy, S. L., Post, R. M., Rapport, D. J., Russell, J. M., Sachs, G. S., \& Zajecka, J. (2000). Development and validation of a screening instrument for bipolar spectrum disorder: The mood disorder questionnaire. American Journal of Psychiatry, 
157(11), 1873-1875. https://doi.org/10.1176/appi.ajp.157.11.1873

Hirschfeld, Robert M.A. (2010). Mood disorder questionnaire: It's impact on the field. Depression and Anxiety, 27(7), 627-630. https://doi.org/10.1002/da.20697

Idulfilastri, R. M. (2018). Pengujian konstruk tes potensi manajerial berdasarkan validitas butir dengan metode factor analysis. Jurnal Muara Ilmu Sosial, Humaniora, Dan Seni, 2(1), 189-197. http://dx.doi.org/10.24912/jmishumsen.v2i1.1597

Isometsä, E., Suominen, K., Mantere, O., Valtonen, H., Leppämäki, S., Pippingsköld, M., \& Arvilommi, P. (2003). The Mood Disorder Questionnaire improves recognition of bipolar disorder in psychiatric care. BMC Psychiatry, 3, 1-4. https://doi.org/10.1186/1471-244X3-8

Karr, J. E., Kibby, M. Y., Jagger-Rickels, A. C., \& Garcia-Barrera, M. A. (2018). Sensitivity and Specificity of an Executive Function Screener at Identifying Children With ADHD and Reading Disability. Journal of Attention Disorders. https://doi.org/10.1177/1087054718763878

Kazdin, A. E. (2000). Encyclopedia of Psychology (3rd ed.). Oxford University Press.

Kementerian Kesehatan. (2018). Hasil utama riskesdas 2018. https://www.depkes.go.id/resources/download/info-terkini/hasil-riskesdas-2018.pdf

Konuk, N., Kiran, S., Tamam, L., Karaahmet, E., Aydin, H., \& Atik, L. (2007). Validation of the Turkish version of the Mood Disorder Questionnaire for screening bipolar disorders. Turk Psikiyatri Dergisi, 18(2), 1-7.

Krach, S. K., McCreery, M. P., \& Guerard, J. (2017). Cultural-linguistic test adaptations: Guidelines for selection, alteration, use, and review. School Psychology International, 38(1), 3-21. https://doi.org/10.1177/0143034316684672

Leung, C. M., Lapyim, C., Yan, C. T. Y., Chan, C. C., Xiang, Y. T., Mak, A. D. P., Fok, M. L. Y., \& Ungvari, G. S. (2016). The Bipolar II depression questionnaire: A self-report Tool for detecting Bipolar II depression. PLoS ONE, 11(3), 1-15. https://doi.org/10.1371/journal.pone.0149752

Sindo. (2019, Maret 30). Memahami mereka yang hidup dengan bipolar. Sindonews. https://nasional.sindonews.com/read/1391291/18/memahami-mereka-yang-hidupdengan-bipolar-1553875392

Ritchie, H., \& Roser, M. (2018). Mental health. University of Oxford. https://ourworldindata.org/mental-health

Sanchez-moreno, J., Villagran, J. M., Gutierrez, J. R., Camacho, M., Ocio, S., Palao, D., Querejeta, I., Gascon, J., Sanchez, G., \& Vieta, E. (2008). Adaptation and validation of the Spanish version of the Mood Disorder Questionnaire for the detection of bipolar disorder. Bipolar Disorders, 10(3), 400-412. https://doi.org/10.1111/j.13995618.2007.00571.x

Smith, N. (2018). Twenty wasted years: Exploring the experience of misdiagnosis within bipolar type two disorder. Cardiff Metropolitan University, 10(2), 1-15. http://espace.mmu.ac.uk/621610/

Søreide, K., Kørner, H., \& Søreide, J. A. (2011). Diagnostic accuracy and receiver-operating characteristics curve analysis in surgical research and decision making. Annals of Surgery, 253(1), 27-34. https://doi.org/10.1097/SLA.0b013e318204a892

Vieta, E., Berk, M., Schulze, T. G., Carvalho, A. F., Suppes, T., Calabrese, J. R., Gao, K., Miskowiak, K. W., \& Grande, I. (2018). Bipolar disorders. Nature Reviews Disease Primers, 4. https://doi.org/10.1038/nrdp.2018.8 
Waleeprakhon, P., Ittasakul, P., Lotrakul, M., Wisajun, P., Jullagate, S., \& Ketter, T. A. (2014). Development and validation of a screening instrument for bipolar spectrum disorder: The Mood Disorder Questionnaire Thai version. Neuropsychiatric Disease and Treatment, 10, 1497-1502. https://doi.org/10.2147/NDT.S67842

Yang, H. chen, Yuan, C. mei, Liu, T. bang, Li, L. jiang, Peng, H. jun, Rong, H., Liao, C. ping, Shen, Q. jie, \& Fang, Y. ru. (2011). Validity of the Chinese version Mood Disorder Questionnaire (MDQ) and the optimal cutoff screening bipolar disorders. Psychiatry Research, 189(3), 446-450. https://doi.org/10.1016/j.psychres.2011.02.007 